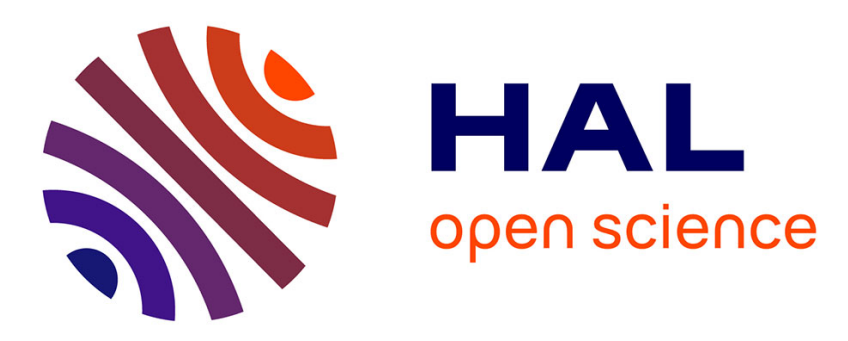

\title{
A Robust Facility Layout Planning Method Considering Temporal Efficiency
}

Eiji Morinaga, Komei Iwasaki, Hidefumi Wakamatsu, Eiji Arai

\section{To cite this version:}

Eiji Morinaga, Komei Iwasaki, Hidefumi Wakamatsu, Eiji Arai. A Robust Facility Layout Planning Method Considering Temporal Efficiency. IFIP International Conference on Advances in Production Management Systems (APMS), Sep 2017, Hamburg, Germany. pp.168-175, 10.1007/978-3-319-669267_20.hal-01707270

\author{
HAL Id: hal-01707270 \\ https://hal.inria.fr/hal-01707270
}

Submitted on 12 Feb 2018

HAL is a multi-disciplinary open access archive for the deposit and dissemination of scientific research documents, whether they are published or not. The documents may come from teaching and research institutions in France or abroad, or from public or private research centers.
L'archive ouverte pluridisciplinaire HAL, est destinée au dépôt et à la diffusion de documents scientifiques de niveau recherche, publiés ou non, émanant des établissements d'enseignement et de recherche français ou étrangers, des laboratoires publics ou privés.

\section{(c)(1)}

Distributed under a Creative Commons Attribution| 4.0 International License 


\title{
A Robust Facility Layout Planning Method Considering Temporal Efficiency
}

\author{
Eiji Morinaga $^{1}$, Komei Iwasaki $^{1,2}$, Hidefumi Wakamatsu $^{1}$, Eiji $^{\text {Arai }}{ }^{1}$ \\ ${ }^{1}$ Division of Materials and Manufacturing Science, Osaka University \\ \{morinaga, komei.iwasaki, wakamatu, arai\}@mapse.eng.osaka-u.ac.jp \\ ${ }^{2}$ Currently, NEC Corporation
}

\begin{abstract}
Facility layout planning (FLP) is an important stage for optimal design of manufacturing systems. A major approach is to define an evaluation index based on distance and find a layout which minimizes it. Temporal efficiency is not considered in this stage but in later stages. The resultant temporal efficiency may not be optimal enough, since decision and optimization in those stages are performed under the fixed layout. For this reason, the authors have developed FLP methods considering temporal efficiency. Those methods provide the optimal layout plan for a fixed production scenario. However, production environments change dynamically in actual manufacturing, and the layout plan is no longer optimal after the changes. In this paper, the conventional method is enhanced considering robustness against the changes.
\end{abstract}

\section{Introduction}

In order to convert data of an artifact generated in product design into an entity and place it on the market as a product with high cost-performance, it is necessary to design a manufacturing system optimally. Facility layout planning (FLP) is an important stage for the design and has been a topic of discussion for a long time [1-3]. In research of FLP, evaluation indices based on distance such as total travel distance and total material handling cost are usually taken into consideration, and optimization based on them is performed by mathematical optimization (quadratic assignment problem [4] and mixed integer programming [5]) or metaheuristics (tabu search [6], simulated annealing [7], genetic algorithm $[8,9]$, etc.). Those indices do not include temporal efficiency which is considered in the stage of production scheduling performed after completing the FLP stage. However, this may result in inadequate optimization from the point of view of the whole system. For example, optimization in terms of total travel distance may cause locating some facilities unnecessarily closer than they are required from the point of view of scheduling and other facilities which are required to be located as close as possible are located apart. For this reason, it is desirable to take temporal efficiency into account in FLP stage.

Consideration of temporal efficiency in FLP stage was discussed by some research groups [10-12]. Those researches dealt with allocation of facilities to pregiven sites, and detailed position and size of facilities were ignored. The authors 
proposed an integrated method for FLP and production scheduling in which the integrated planning problem was formulated as a mixed integer programming which minimizes makespan and includes detailed position and size of facilities as decision variables and constants [13]. However, transportation routes were not taken into consideration and transportation times for evaluating temporal efficiency were calculated roughly based on the Manhattan distance between facilities. In addition, loading/unloading points of facilities were not considered either. Therefore, the authors also proposed an FLP method considering these problems [14]. Due to difficulty of describing the shortest transportation route by linear equations/inequalities mathematically, genetic algorithm (GA) was taken for optimization of facility layout plan in which finding the optimal routes and makespan based on the routes was performed for each layout plan.

Those methods provide the optimal layout plan for a fixed production scenario. However, production environments change dynamically in actual manufacturing, and the layout plan is no longer optimal after the changes. An approach for solving this problem is to adopt the concept of robustness against the changes [15] and robust FLP based on enumerative method [16], branch-andbound method [17], fuzzy theory [18], etc. has been discussed. In this paper, the FLP method considering temporal efficiency and routing is enhanced from the point of view of robustness.

\section{Manufacturing System Taken into Consideration}

This research deals with job-shop production with $J$ kinds of jobs and $F$ facilities. Job $j \in\{1, \ldots, J\}$ needs $O_{j}$ operations. Operation $o \in\left\{1, \ldots, O_{j}\right\}$ of job $j$ is processed by facility $f_{j o} \in\{1, \ldots, F\}$. Width and depth of facility $f$ are $w_{f}$ and $d_{f}$. Each facility has loading and unloading points. Those facilities are located in the production area which has a rectangular shape of width $W$ and depth $D$.

\section{Outline of FLP Considering Temporal Efficiency}

This section provides an outline of the FLP method considering temporal efficiency where transportation routes and loading/unloading points of facilities are also considered [14]. Because it is impossible to describe the shortest transportation route by linear equations/inequalities mathematically and to formulate the problem of finding the optimal layout based on temporal efficiency as a mathematical optimization problem, optimization of facility layout plan is carried out iteratively by GA and routing and minimization of makespan are performed for each layout plan (Fig. 1). It is necessary to represent a layout plan as an individual in GA. For this purpose, the production area is divided up into a grid of squares with sides one meter and each cell has its ID number (Fig. 2). It is possible to represent a layout plan as an individual by defining the structure of chromosome as $F$ pairs of two numbers, where the second number of the $f$-th pair is the number of clockwise rotation by 90 degrees, and the first number is the ID number of the cell on which the upper left part of facility $f$ (Fig. 3). 


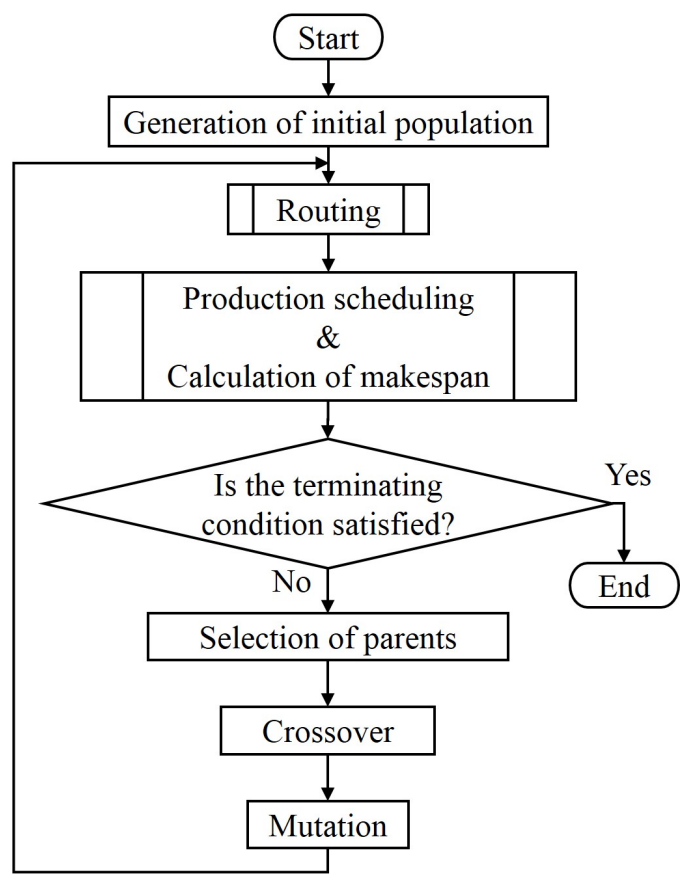

Fig. 1. Flowchart of FLP considering routing and temporal efficiency using GA[14].

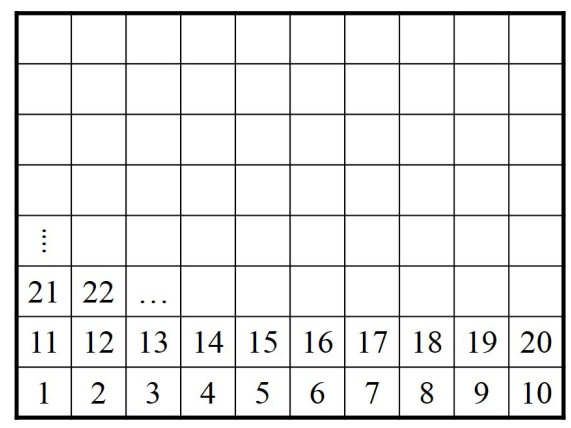

Fig. 2. Production area divided up into a grid of squares[14]. 

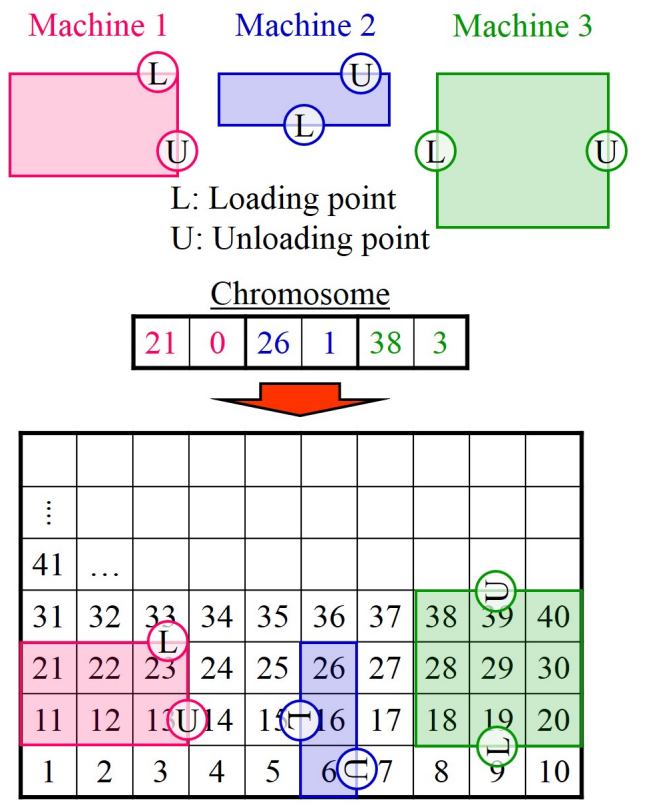

Fig. 3. Chromosome representation of a layout plan[14].

For a layout plan represented as stated above, the shortest route between two facilities can be obtained by using Dijkstra's method. Transportation time can be obtained by dividing the length of the route by the velocity of an automated guided vehicle (AGV).

Production scheduling for a layout plan should be completed in a short time, since this process has to be performed many times. For this reason, mathematical optimization is not adopted but GA is utilized also for this process.

\section{Robust FLP Method Considering Temporal Efficiency and Routing}

This section describes enhancement of the conventional method for robust FLP. In the conventional method, makespan of the optimal schedule for the given production scenario was taken as a temporal index. To take various scenarios and obtain a robust layout, the following index is adopted:

$$
\sum_{i=1}^{S} M_{i} P_{i}
$$

where $M_{i}$ stands for the makespan of the optimal schedule for the $i$-th one in the given set of production scenarios the cardinality of which is $S$, and $P_{i}$ is the probability of the scenario. Because a production scenario is defined as a 
Table 1. Dimensions of facilities. "N", "E", "S" and "W" stand for "North", "East",

"South" and "West", respectively.

\begin{tabular}{|l|c|c|c|c|c|c|c|}
\hline Facility $m$ & 1 & 2 & 3 & 4 & 5 & 6 & 7 \\
\hline Width $w_{f}[\mathrm{~m}]$ & 2 & 3 & 4 & 3 & 5 & 4 & 2 \\
\hline Depth $d_{f}[\mathrm{~m}]$ & 2 & 2 & 2 & 3 & 4 & 3 & 2 \\
\hline Loading/ & $\mathrm{N} /$ & $\mathrm{N} /$ & $\mathrm{N} /$ & $\mathrm{N} /$ & $\mathrm{N} /$ & $\mathrm{N} /$ & $\mathrm{N} /$ \\
Unloading & $\mathrm{N}$ & $\mathrm{E}$ & $\mathrm{W}$ & $\mathrm{S}$ & $\mathrm{N}$ & $\mathrm{N}$ & $\mathrm{N}$ \\
\hline
\end{tabular}

Table 3. Required processing time [min].

\begin{tabular}{|c|c|c|c|c|c|c|c|}
\hline \multirow{2}{*}{ Job $j$} & \multicolumn{6}{|c|}{ Operation $o$} \\
\cline { 2 - 7 } & 1 & 2 & 3 & 4 & 5 & 6 & 7 \\
\hline 1 & 5 & 3 & 2 & 7 & 6 & 4 & 5 \\
\hline 2 & 3 & 6 & 5 & 8 & 4 & 3 & 3 \\
\hline 3 & 4 & 4 & 3 & 5 & 2 & 1 & 4 \\
\hline 4 & 6 & 5 & 4 & 3 & 8 & 5 & 6 \\
\hline 5 & 2 & 3 & 4 & 3 & 1 & 4 & 2 \\
\hline
\end{tabular}

Table 2. Processing sequence $m_{j o}$.

\begin{tabular}{|c|c|c|c|c|c|c|c|c|}
\hline \multirow{2}{*}{ Job $j$} & \multicolumn{6}{|c|}{ 年eration $o$} \\
\cline { 2 - 7 } & 1 & 2 & 3 & 4 & 5 & 6 & 7 \\
\hline 1 & 3 & 6 & 2 & 4 & 5 & 1 & 7 \\
\hline 2 & 2 & 3 & 5 & 1 & 4 & 7 & 6 \\
\hline 3 & 3 & 4 & 1 & 7 & 5 & 2 & 6 \\
\hline 4 & 2 & 6 & 3 & 4 & 7 & 5 & 1 \\
\hline 5 & 3 & 7 & 5 & 1 & 4 & 6 & 2 \\
\hline
\end{tabular}

Table 4. Parameters of GA.

\begin{tabular}{|c|c|}
\hline Population size & 300 \\
\hline Maximum \# of alternation & 200 \\
\hline Crossover probability & 0.7 \\
\hline Mutation probability & 0.03 \\
\hline
\end{tabular}

combination of the number of production of jobs in this research, $P_{i}$ is given by

$$
P_{i}=\Pi_{j=1}^{J} p_{j}^{i},
$$

where $p_{j}^{i}$ is the probability of the number of production of the $j$-th kind of job specified by the $i$-th production scenario. By introducing this evaluation index, facility layout considering various production scenarios can be obtained.

This new index increases the required number of performing production scheduling by $S$ times. It is unreasonable to perform scheduling using GA from the point of view of computational load. Therefore, in this method, scheduling is performed based on the simulation approach using a dispatching rule.

\section{$5 \quad$ Numerical Example}

The proposed method was applied to a simple example of $F=7, J=5, O_{j}=7$, $W=D=15[\mathrm{~m}]$. It was assumed that there were sufficient number of AGVs and the velocity of an AGV was given as $3[\mathrm{~m} / \mathrm{min}]$. Dimensions of the facilities were given as shown in Table 1, where "North" means that the loading/unloading point is located in the center of the north part of the facility without rotation. Processing sequence and required processing time were given as shown in Tables 2 and 3. Optimization of facility layout by GA was performed with the parameters shown in Table 4 . The shortest processing time (SPT) rule was adopted as a dispatching rule for production scheduling.

The number of production of each kind of job was assumed to be 4,5 or 6 , and their probability were given as $0.3,0.4$ and 0.3 , respectively. The number of 


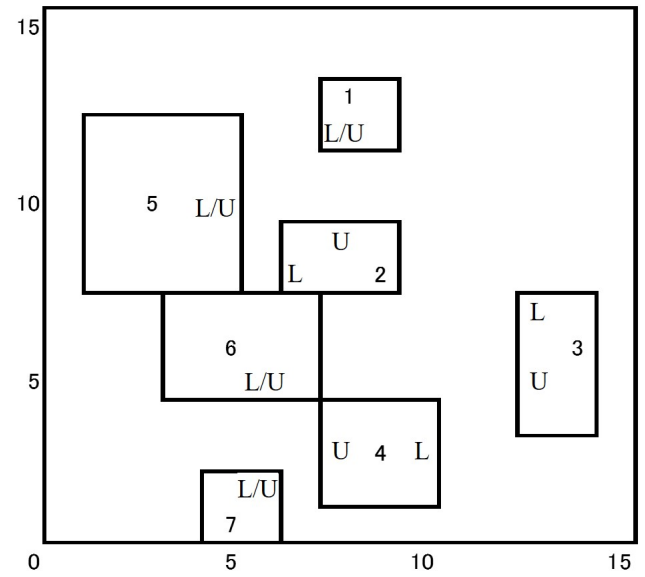

Fig. 4. Facility layout obtained by the integrated method considering only one production scenario.

Table 5. Makespan under the stan- Table 6. Value of evaluation index (1). dard scenario.

\begin{tabular}{|l|l|}
\hline Fig. 4 & 10299 \\
\hline Fig. 5 & 10799 \\
\hline
\end{tabular}

$$
\begin{array}{|l|l|}
\hline \text { Fig. } 4 & 11264 \\
\hline \text { Fig. } 5 & 10793 \\
\hline
\end{array}
$$

production scenarios $S$ was $3^{5}=243$. Figure 4 shows the facility layout obtained by the integrated method considering only one scenario (called as standard scenario in this paper) where the number of production is 5 for all kinds of job, and Fig. 5 shows the layout obtained by the proposed method considering all the scenarios (243 scenarios).

Table 5 shows the values of makespan calculated for the two layouts under the standard scenario, and Table 6 shows the values of the evaluation index (1) calculated for the two layouts considering all the scenarios, respectively. Figure 6 shows the values of makespan calculated for the two layouts under each of the scenarios. It can be confirmed that better makespan can be achieved with the layout obtained by the proposed method under many scenarios, in other words, the proposed method provides a robust layout.

\section{Conclusion}

In this paper, the conventional FLP method considering temporal efficiency and routing has been improved from the point of view of robustness. Sum of product of the probability of production scenario and makespan achieved under the scenario has been defined as an evaluation index for taking robustness into con- 


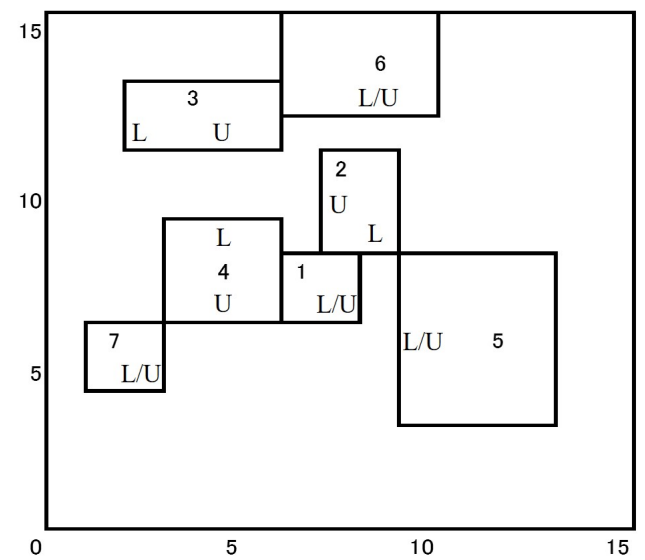

Fig. 5. Facility layout obtained by the integrated method considering various production scenarios.

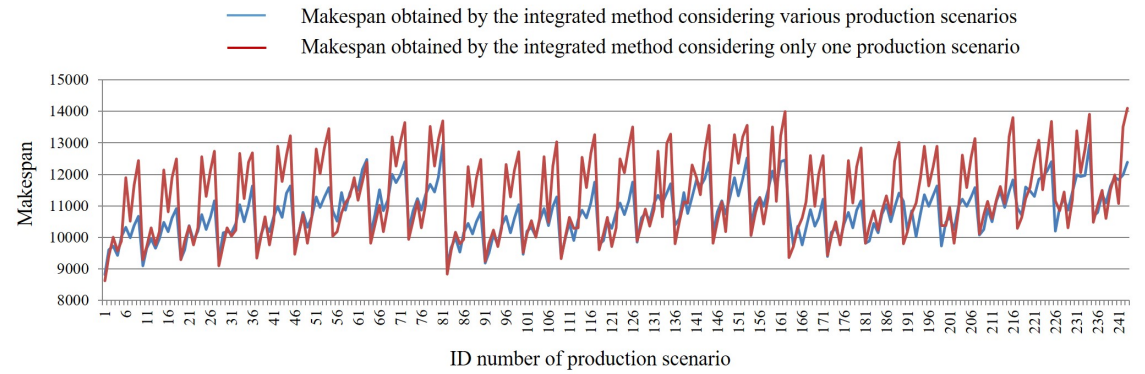

Fig. 6. Makespan for the obtained layouts on each production scenario.

sideration. Simulation approach has been adopted for performing production scheduling in a reasonable time, since the new index causes drastic increase of computational load in production scheduling. The effectiveness of the proposed method was illustrated by a numerical example.

To make the proposed method practical, it is necessary to reduce computational load further. The sampling approach [19] would be effective for this problem, and this issue will be discussed in a future work.

\section{References}

1. Meller, R.D. and Gau, K.Y.: The Facility Layout Problem: Recent and Emerging Trends and Perspectives, Journal of Manufacturing Science, 15, 351-366 (1996) 
2. Benjaafar, S., Heragu, S.S. and Irani, S.A.: Next Generation Factory Layouts: Research Challenges and Recent Progress, Interfaces, 32, 58-76 (2002)

3. Drira, A., Pierreval, H. and Hajri-Gabouj, S.: Facility layout problems: A survey, Annual Reviews in Control, 31, 255-267 (2007)

4. Lawler, E.L.: The Quadratic Assignment Problem, Management Science, 19, 586599 (1963)

5. Meller, R.D., Narayanan, V. and Vance, P.H.: Optimal facility layout design, Operations Research Letters, 23, 117-127 (1999)

6. Cheng, W.C. and Kouvelis, P.: An improved tabu search heuristic for solving facility layout design problems, International Journal of Production Research, 34, 2565-2585 (1996)

7. Chwif, L., Barretto, M.R.P. and Moscato, L.A.: A solution to the facility layout problem using simulated annealing, Computers in Industry, 36, 125-132 (1998)

8. Banerjee, P. and Zhou, Y.: Facilities layout design optimization with single loop material flow path configuration, International Journal of Production Research, 33, 183-203 (1995)

9. Hicks, C.: A genetic algorithm tool for designing manufacturing facilities in the capital goods industry, International Journal of Production Economics, 90, 199$211(2004)$

10. Fujihara, Y. and Osaki, H.: A Facility Layout Method Linked to Production Scheduling, Transactions of the Japan Society of Mechanical Engineers, C, 63, 293-303 (1997) (In Japanese)

11. Hino, R. and Moriwaki, T.: Resource Reallocation Based on Production Scheduling (1st report), Journal of the Japan Society for Precision Engineering, 69, 655-659 (2003) (In Japanese)

12. Inagawa, T.: Research on facility layout with production scheduling including transportation time, Master's Thesis, Hosei University (2005) (In Japanese)

13. Morinaga, E., Shintome, Y., Wakamatsu, H. and Arai, E.: Facility Layout Planning with Continuous Representation Considering Temporal Efficiency, Transactions of the Institute of Systems, Control and Information Engineers, 29, 408-413 (2016)

14. Morinaga, E., Iwasaki, K., Wakamatsu, H. and Arai, E.: A Facility Layout Planning Method Considering Routing and Temporal Efficiency, Proceedings of International Symposium on Flexible Automation 2016, 193-198 (2016)

15. Moslemipour, G., Lee, T.S. and Rilling, D.: A review of intelligent approaches for designing dynamic and robust layouts in flexible manufacturing systems, International Journal of Advanced Manufacturing Technology, 60, 11-27 (2012)

16. Rosenblatt, M.J. and Lee, H.L.: A robustness approach to facilities design, International Journal of Production Research, 25, 479-486 (1987)

17. Kouvelis, P., Kurawarwala, A.A. and Gutierrez, G.J.: Algorithms for robust single and multiple period layout planning for manufacturing systems, European Journal of Operational Research, 63, 287-303 (1992)

18. Aiello, G. and Enea, M.: Fuzzy approach to the robust facility layout in uncertain production environments, International Journal of Production Research, 39, 4089$4101(2001)$

19. Yoshitomi, Y., Ikenoue, H., Takeba, T. and Tomita, S.: Genetic Algorithm in Uncertain Environments for Solving Stochastic Programming Problem, Journal of the Operations Research Society of Japan, 43, 266-290 (2000) 